\title{
Synthesis, optical, photophysical and solvatochromoic properties on the D-r-A dye with benzo[b]thiophene moiety
}

\section{Lili Feng}

China University of Mining and Technology

\section{Pengyu Wang}

China University of Mining and Technology

Zhuo Chen ( $\nabla$ chenzhuo@mail.ipc.ac.cn )

Technical Institute of Physics and Chemistry CAS: Technical Institute of Physics and Chemistry

Shuhui Bo ( $\sim$ boshuhui@muc.edu.cn )

Minzu University of China https://orcid.org/0000-0002-3695-6122

\section{Research Article}

Keywords: $\mathrm{D}-\pi-\mathrm{A}$ dye, Positive solvatochromism, Intramolecular charge transfer (ICT), pH switch, Zwitterion

Posted Date: February 23rd, 2021

DOl: https://doi.org/10.21203/rs.3.rs-217458/v1

License: (9) This work is licensed under a Creative Commons Attribution 4.0 International License. Read Full License 


\section{Abstract}

A D-ז-A solvatochromic chromophore based on the novel benzo[b]thiophene moiety donor, the tricyanofuran (TCF) acceptor, alkoxy chains modified aniline and extended $\pi$-conjugations have been synthesized and systematically investigated in this paper. The absorption and fluorescence emission spectra of the dye in different polar solvents were studied. A positive solvatochromism of the dye was observed also with a color change of the solution that could be observed with the naked eye. The HOMO and LUMO values of the dye was obtained by both cyclic voltammetry and theoretical calculations. By adding acid/base into the DMSO solution of the dye, the color, absorption and fluorescence emission spectra of the solution showed the good characteristics of $\mathrm{pH}$ switch, which has potential applications for the molecular sensors and probe.

\section{Introduction}

The effect of solvent on the absorption and fluorescence properties of organic molecules is an area worthy of study. The solvents affect the structure, excited state properties, and charge distribution characteristics of organic molecules. The phenomenon that the solution interacts with the organic molecules to produce a color change is solvatochromism, which can happen in many compounds, such as fluorescent dyes [1, 2], MOFs [3], ionic liquids [4] and hybrid materials [5, 6]. With the change of the polarity of the solvent molecule, the absorption spectrum and the fluorescence emission spectrum of the solution will change accordingly. The D- $\pi-A$ charge transfer dye has attracted much attention because of its usefulness as a solvent polarity measurement [7]. Charge transfer dyes are also used as sensors in determining solvent polarity $[8,9]$, and the concept of using solvatochromic dyes as optical chemical sensors has played an important role in the field of molecular sensors. In various hybrid solar cells, dyesensitized solar cells (DSSCs) have attracted extensive interests for their good commercial prospects [10-12], and the typical structure of metal-free organic sensitizers generally consists of the electron donor (D), $\pi$-bridge and the electron acceptor (A) to form a D- $\pi-A$. In addition, they are also used as photoluminescent materials for laser [13], the production of molecular switches in molecular electronics $[14,15]$, optical antennas [16, 17], and organic light emitting diodes [18, 19], etc.

Based on our previous work in organic second-order nonlinear optical materials [20-23], we have been paying close attention to the solvatochromic effect of organic molecules containing the D- $\pi-A$ structure of the tricyanofuran acceptor and the relative changes in its absorption and fluorescence spectra. The strong electron-withdrawing ability of cyano group in the same plane of 2-(3-cyano-4,5,5-trimethylfuran-2 $(5 H)$-ylidene)malononitrile (TCF) greatly increases the nonlinear hyperpolarizability $(\beta)$ of the chromophore molecule using TCF as an electron acceptor [24], thereby increasing the macroscopic second-order nonlinear optical properties of the material $[25,26]$. Benzo[ $b]$ thiophene as the electron donor attracted our attention because the rigidified polyene conduit of the fused benzo group provides a planar geometry, which allows effective intramolecular charge transfer. 
In this paper, a D- $\pi-A$ charge transfer dye A containing TCF acceptor group and benzo[ $b]$ thiophen-6-amine donor group was designed and synthesized. The photophysical properties, electrochemical properties and solvatochromic effect were systematically studied. Dyes having a D-ח-A structure are susceptible to external environmental influences such as solvent polarity and solution $\mathrm{pH}$ value. Furthermore, we also examined the changes in absorption and fluorescence spectra of the dye in DMSO due to $\mathrm{pH}$ changes which are adjusted using the acid/base in the reversible process.

\section{Experimental}

${ }^{1} \mathrm{H}$ NMR and ${ }^{13} \mathrm{C}$ NMR spectra were determined by an Advance Bruker 400M (400 MHz) NMR spectrometer (tetramethylsilane as internal-reference). The MS spectra were obtained on MALDI-TOF (Matrix Assisted Laser Desorption/lonization of Flight) on BIFLEXIII (Broker Inc.) spectrometer. UV-Vis spectra were measured on a UV-1800 spectrophotometer manufactured by Shimadzu Instruments (Suzhou) Co., Ltd. Fluorescence spectra were measured on an F-4600 spectrophotometer manufactured by Hitachi. The DFT calculations using Gaussian 03 were carried out at the hybrid B3LYP level by employing the split valence $6-31 \mathrm{~g}(\mathrm{~d})$ basis set.

\subsection{Materials}

Tetrabutylammonium hydroxide (25\%) methanol (an aqueous solution containing $25 \%$ methanol) was purchased from Beijing Ouhe Technology Co., Ltd. Trifluoroacetic acid was purchased from Beijing Chemical Plant, and its purity was analytically pure. All solvents used were of analytical grade and were used without further drying or purification. All chemicals, commercially available, are used without further purification unless stated. The DMF, toluene and THF were freshly distilled prior to its use. 2-

Dicyanomethylene-3-cyano-4-methyl-2,5-dihydrofuran (TCF) acceptor was prepared according to the literature [27].

\subsection{Electrochemical measurement}

The redox and oxidation potential were measured by cyclic voltammetry on a $\mathrm{CHI} 660 \mathrm{C}$ electrochemical workstation. The cyclic voltammetry experiment was carried out in a solution containing $\mathrm{CH} 2 \mathrm{Cl} 2$. The working electrode is glassy carbon, the counter electrode is $\mathrm{Pt}$, and the $\mathrm{Ag} / \mathrm{AgCl}$ electrode is used as the reference electrode. The scan rate is usually $100 \mathrm{mV} / \mathrm{s} .1 \mathrm{mM}$-tetrabutylammonium perchlorate is used as a supporting electrolyte.

\subsection{Synthesis of the dye A}

The dye A was prepared and confirmed in a similar manner as described in the previous work [28]. Compound 2 was obtained by Pt catalyzed Hartwig-Buchwald coupling reaction using compound 1, and the coupling between TCF acceptor and benzo[b]thiophene donor was operated by Knoevenagel condensation reaction. 


\section{Results And Discussion}

\subsection{Solvated discoloration properties}

The dye A were successfully obtained by condensing aldehydes 6-(dibutylamino)benzo[b]thiophene-2carbaldehyde $\mathbf{3}$ with a strong TCF electron acceptor in ethanol. The chemical structures of all the intermediates and dye $\mathrm{A}$ were characterized by ${ }^{1} \mathrm{H}$ NMR, ${ }^{13} \mathrm{C}$ NMR and MALDI-TOF.

The absorption and emission spectra of dye $\mathbf{A}$ in several solvents with different polarities are shown in Fig. 1. The solvent-dependent absorption and fluorescence emission $\lambda_{\max , \text { abs }}$ and $\lambda_{\max \text {, em }}$ and $E_{\mathrm{T}}(30)$ of the dye in various solvents are listed in Table 1 . As the solvent polarity increased, a bathochromic shift observed. This is the positive solvatochromism (Fig. 1a). The UV-Vis absorption peaks of the dye $\mathbf{A}$ showed a shift with the solvent polarity, which extended from $618 \mathrm{~nm}$ in toluene to $643 \mathrm{~nm}$ in chloroform. The emission peaks of dye A also showed shifts with solvent polarity, which extended form $690 \mathrm{~nm}$ in toluene to $746 \mathrm{~nm}$ in methanol. The fluorescence intensity is relatively low in the long wavelength direction. This is because the smaller the energy gap, the more serious the nonradiative transition. These results demonstrated that a strong $\pi-\pi^{\star}$ transition with charge transfer exists in the dye $\mathbf{A}$. The intramolecular charge transfer (ICT) is from benzo[b]thiophene moiety donor to the TCF acceptor is strongly enhanced upon excitation from the phenomenon of obvious bathochromic shift of the fluorescence peaks in polar solvents. The positive solvatochromism is because the dye $\mathbf{A}$ has larger dipole moment in the excited state than in the ground state. The above phenomenon indicates that the dye exhibits strong solvatochromic property. As the polarity of the solvent increases, the dipole moment of the molecule changes greatly after excitation, hence color change of solvent. The dipole action of the excited state in a highly polar solvent is more stable than the dipole action of the ground state in a small polar or non-polar solvent. In the solvents of different polarities, as the dipole moment of the dye increases, the positive solvatochromism is observed, and the redshift of the absorption peak and the emission peak appear (Fig. 1). However, in the chloroform and DMF, the emission peak delivers blueshift, and the dipole moment decreases in the electronic transition, resulting in negative solvatochromism. The reason may be that as the solvent polarity increases, the ground state of the dye changes. It is more stable than the excited state. 
Table 1

$\lambda_{\max , a b s}, \lambda_{\max , \text { em }}$ and $\mathrm{E}_{\mathrm{T}}(30)$ of solvent-dependent absorption and fluorescence emission of the molecule in various solvents

\begin{tabular}{|llll|}
\hline Solvent & $\lambda_{\text {max, abs }}(\mathrm{nm})$ & $\boldsymbol{\lambda}_{\max , \mathrm{em}^{\mathrm{a}}}{ }^{(\mathrm{nm})}$ & $\mathrm{E}_{\mathrm{T}}(\mathbf{3 0})(\mathrm{kcal} / \mathrm{mol})$ \\
\hline Toluene & 618 & 690 & 33.9 \\
\hline THF & 624 & 731 & 37.4 \\
\hline Chloroform & 659 & 689 & 39.1 \\
\hline Acetone & 629 & 732 & 42.2 \\
\hline DMF & 657 & 672 & 43.8 \\
\hline Acetonitrile & 634 & 736 & 45.6 \\
\hline Ethanol & 640 & 745 & 51.9 \\
\hline Methanol & 643 & 746 & 55.4 \\
\hline a Excitation wavelength is the maximum absorption wavelength in each solvent.
\end{tabular}

Since the photophysical properties of D- $\pi-A$ in solution depend on the polarity of solvent, we studied the maximum absorption and fluorescence of dye $\mathrm{A}$ in different polar solvents depending on the polarity of solvent. In Fig. 2, the dependence of the absorption and emission peaks of dye A on ET (30) solvent polarity parameter can be fitted to almost linear function. As the solvent polarity parameter increased, the bathochromic shift exhibited. This phenomenon indicated that dye A represented positive solvatochromism, where the ground state is less polar than the excited state. The charge delocalization from the electron-donating benzo[b]thiophene moiety to the electron-accepting the tricyanofuran (TCF) may be attributed to the polar ground state and ICT properties of the molecule, which leads to the red shift of the maximum absorption $[29,30]$.

As shown in Fig. 2, the fitting slope (2.05) in $b$ is greater than the fitting slope in a (1.15), which indicates that the solvatochromism effect in emission is stronger than the solvatochromism in absorption. Fluorescence has stronger solvent polarity dependence since the relaxation of the originally formed excited state leads to a large amount of charge redistribution, the ICT excited state has a larger dipole moment than the ground state [31-33].

Figure 3 is a photograph of the color change of dye in the solution of the above eight solvents. It can be observed that as the polarity of the solvent changes, the color of the solution also undergoes obvious change. Furthermore, the color of the dye $\mathrm{A}$ in $\mathrm{CHCl} 3$ solution changes most obviously.

\subsection{Theoretical calculation and electrochemical properties of the dye}


DFT calculations have been carried out on dye A using B3LYP/6-311G* geometries by means of Gaussian 03 (G03). Figure 4 showed the electron distribution of the HOMO and LUMO energy level of the dye. It indicates that the electron density is uniformly distributed along the donor and $\pi$-bridge moiety at the HOMO state. While at the LUMO state, the electrons were shifted to the $\pi$-bridge and acceptor moiety due to the intramolecular charge transfer. The HOMO-LUMO energy gap of the dye A obtained from DFT calculations are summarized in Table 2. The HOMO-LUMO energy gap was used to understand the charge transfer interaction occurring in a chromophore molecule.

Table 2

Calculated properties and electrochemical properties of the dye

\begin{tabular}{|llllll|}
\hline HOMO/eV & LUMO/eV & $E_{g e} / e V$ & $E_{o x} / V$ & $E_{\text {red }} / V$ & $E_{g e} / e V$ \\
\hline-5.67 & -3.31 & 2.36 & 0.85 & -0.66 & 1.51 \\
\hline
\end{tabular}

The electrochemical reduction/oxidation behavior of the dye A was studied by cyclic voltammetry (CV). As shown in Fig. 5 , the dye $A$ showed an oxidation reversible wave with half-wave potentials $E_{1 / 2}=$ $0.5($ Eox + Ered) at about $0.85 \mathrm{~V}(\mathrm{vs}$. $\mathrm{Ag} / \mathrm{AgCl})$, while an irreversible reduction wave with potential at about $0.66 \mathrm{~V}$ corresponding to the donor and acceptor group, respectively.

\section{$3.2 \mathrm{pH}$-induced switching in absorption and fluorescence spectra with color change of solution}

The dye was dissolved in a solution of $1 \times 10^{-5} \mathrm{~mol} / \mathrm{L}$ with DMSO as the solvent, and acid $\left(\mathrm{CF}_{3} \mathrm{COOH}\right) /$ base $\left((\mathrm{Bu})_{4} \mathrm{~N}(\mathrm{OH})\right)$ was added to the solution dropwise. The interaction in solutions after adding acid and base was studied by spectrophotometer and change of solution color. Figure 6 shows the UV-Vis absorption and fluorescence spectral changes of the dye in an acid/base DMSO solution.

In the Fig. 6(a), the absorption intensity at $650 \mathrm{~nm}$ was significantly reduced after adding base to the solution of the dye. The color changed from blue to yellow, as shown in Fig. 7(a) and Fig. 7(b). The absorption intensity at $650 \mathrm{~nm}$ was also reduced by adding acid to the solution in Fig. 6(a), but much higher than the solution adding base (yellow) as shown in Fig. 7(c). After the solution was added with the base, the fluorescence spectrum also showed the same result as the UV-Vis spectrum in Fig. 6(b). When the solution was added with the acid, the peak of fluorescence spectrum decreased slightly, but the peak of fluorescence spectrum adding the base almost disappeared.

Then, upon addition of acid or base to the dye A DMSO solution in Fig. 7, the yellow solution or the light green solution of dye $\mathbf{A}$ became gradually blue and recovered completely back to the initial state, as shown in Fig. 8. The chromotropic behavior of solvents can be explained by the extreme resonance structure: zwitterions [13]. The phenomenon indicates that when DMSO is used as a solvent, addition of acid or base into the dye A solution is reversible. It may be that $\mathrm{H}^{+}$or $\mathrm{OH}^{-}$induces the formation of 
zwitterion by the addition of acid/base, and the structure of the molecule is restored by adding base/acid. The comparison test proves that DMSO does not react with the molecule, $\mathrm{CF}_{3} \mathrm{COOH}$ and $\mathrm{Bu}_{4} \mathrm{~N}(\mathrm{OH})$.

The positive solvatochromism for dye $\mathbf{A}$ showed that the charge transfer direction is from benzo[b]thiophene moiety to TCF, which indicated that the molecular ground state is neutral structure [34]. When the dye A in DMSO is added the base or acid, the zwitterionic was formed. The chemical structures of zwitterionic and neutral were as shown in Fig. 9. The above reversible process with acid/base trigger may be due to the mutual transformation of neutral and zwitterionic structures.

\section{Conclusions}

The D- $\pi-A$ solvatochromic charge transfer dye A were synthesized by a stepwise route involving a Pt catalyzed Hartwig-Buchwald coupling reaction and Knoevenagel condensation reaction. A positive solvatochromism is observed in polar solvents due to the dipole moment of the dye molecule. The HOMO and LUMO energy level values of the dye $\mathbf{A}$ can be obtained by both cyclic voltammetry and theoretical calculations. The solvatochromic effect of the dye as the probe can be applied in detecting solvent polarity. The organic acid and base triggered molecular switch has been developed by reversible structure of dye after adding acid/base.

\section{Declarations}

\section{Acknowledgements}

We are grateful to the National Natural Science Foundation of China (No. U1733106), the Beijing Municipal Natural Science Foundation (No. 4192061), the Beijing Talents foundation (2018000021223ZK45), and the Youth Innovation Promotion Association of the Chinese Academy of Sciences (2017033) for the financial support.

\section{References}

1. C. Reichardt, Salvatochromic dyes as solvent polarity indicators. Chem. Rev. 94(8), 2319-2358 (1994)

2. Y.X. Li, T.F. Tan, S.R. Wang, Y. Xiao, X.G. Li, Highly solvatochromic fluorescence of anthraquinone dyes based on triphenylamines. Dyes Pigments 144, 262-270 (2017)

3. S. Gao, L.M. Zhao, L. Han, Z.J. Zhang, H. Zhao, Synthesis, structure and characterization of two solvatochromic metal-organic frameworks for chemical-sensing applications. Crystengcomm 20(16), 2237-2240 (2018)

4. J.C. De Jesus, P.A.R. Pires, R. Mustafa, N. Riaz, O.A. Seoud, Experimental and theoretical studies on solvation in aqueous solutions of ionic liquids carrying different side chains: the n-butyl-group versus the methoxyethyl group. Rsc Adv 7(26), 15952-15963 (2017) 
5. Y.K. Jo, B.H. Choi, C.S. Kim, H.J. Cha, Diatom-Inspired Silica Nanostructure Coatings with Controllable Microroughness Using an Engineered Mussel Protein Glue to Accelerate Bone Growth on TitaniumBased Implants. Adv Mater 29(46), 1704906 (2017)

6. C. Kaewtong, S. Kampaengsri, T. Tuntulani, B. Pulpoka, A solvatochromic-based sensor for chromium (III) in real systems. New J Chem 42(12), 9930-9934 (2018)

7. Y.P. Zhang, C.S. Liang, S.M. Jiang, A solvatochromic cyanostilbene derivative as an intensity and wavelength-based fluorescent sensor for water in organic solvents. New J Chem 41(16), 8644-8649 (2017)

8. Z.G. Zhou, A. Wakamiya, T. Kushida, S. Yamaguchi, Planarized Triarylboranes: Stabilization by Structural Constraint and Their Plane-to-Bowl Conversion. J. Am. Chem. Soc. 134(10), 4529-4532 (2012)

9. Z.M. Hudson, X.Y. Liu, S.N. Wang, Switchable Three-State Fluorescence of a Nonconjugated DonorAcceptor Triarylborane. Org. Lett. 13(2), 300-303 (2011)

10. C.Y. Chen, M.K. Wang, J.Y. Li, N. Pootrakulchote, L. Alibabaei, C.H. Ngoc-le, J.D. Decoppet, J.H. Tsai, C. Gratzel, C.G. Wu, S.M. Zakeeruddin, M. Gratzel, Highly Efficient Light-Harvesting Ruthenium Sensitizer for Thin-Film Dye-Sensitized Solar Cells. ACS Nano 3(10), 3103-3109 (2009)

11. J. Song, J. Xu, Density functional theory study on D- $\pi$-A-type organic dyes containing different electron-donors for dye-sensitized solar cells. Bull. Bulletin of the Korean Chemical Society 34(11), 3211-3217 (2013)

12. L. Han, X.Z. Meng, Y.A. Ke, H.Q. Ye, Y.H. Cui, Novel D- $\pi-A$ benzocarbazole dyes with simple structures for efficient dye-sensitized solar cells. J Photochem Photobio A: Chemistry 376, 127-134 (2019)

13. T.A. Khattab, B.D.B. Tiu, S. Adas, S.D. Bunge, R.C. Advincula, Solvatochromic, thermochromic and pHsensory DCDHF-hydrazone molecular switch: response to alkaline analytes. RSC Adv 6(104), 102296-102305 (2016)

14. T.A. Khattab, Novel solvatochromic and halochromic sulfahydrazone molecular switch. J Mol Stru 1169, 96-102 (2018)

15. V. Diemer, H. Chaumeil, A. Defoin, P. Jacques, C. Carre, Synthesis of 4-[N-methyl-4-pyridinio]-phenolate (POMP) and negative solvatochromism of this model molecule in view of nonlinear optical applications. Tetrahedron Lett. 46(28), 4737-4740 (2005)

16. G. McDermott, S.M. Prince, A.A. Freer, A.M. Hawthormthwaite-Lowless, M.Z. Papiz, R.J. Cogdell, Isaacs NW. Crystal structure of an integral membrane light-harvesting complex from photosynthetic bacteria. Nature 1995;374(6522): 517 - 21

17. N. Maruo, M. Uchiyama, T. Kato, T. Arai, N. Nishino, H. Akisada, Hemispherical synthesis of dendritic poly(L-lysine) combining sixteen free-base porphyrins and sixteen zinc porphyrins. Chem. Commun. 20, 2057-2058 (1999)

18. F.H. Li, W.L. Jia, S. Wang, Y.Q. Zhao, Z.H. Lu, Blue organic light-emitting diodes based on Mes(2)B [p4,4 '-biphenyl-NPh(1-naphthyl)]. J of Appl Phys 103(3), 034509 (2008) 
19. W.L. Jia, D.R. Bai, T. McCormick, Q.D. Liu, M. Motala, R.Y. Wang, C. Seward, Y. Tao, S. Wang, Threecoordinate organoboron compounds BAr2R (Ar = mesityl, $\mathrm{R}=$ 7-azaindolyl-or 2,2'-dipyridylaminofunctionalized aryl or thienyl) for electroluminescent devices and supramolecular assembly. Chemistry- A European Journal 10(4), 994-1006 (2004)

20. Z. Chen, A.R. Zhang, H.Y. Xiao, F.Y. Huo, Z. Zhen, X.H. Liu, S.H. Bo, Tailoring the chemical structures and nonliear optical properties of julolidinyl-based chromophores by molecular engineering. Dyes Pigments 173, 107876 (2020)

21. Y.H. Yang, H.R. Wang, F.G. Liu, D. Yang, S.H. Bo, L. Qiu, Z. Zhen, X.H. Liu, The synthesis of new double-donor chromophores with excellent electro-optic activity by introducing modified bridges. Phys. Chem. Chem. Phys. 17(8), 5776-5784 (2015)

22. M.Q. He, T.M. Leslie, J.A. Sinicropi, Synthesis of chromophores with extremely high electro-optic activity. 1. Thiophene-bridge-based chromophores. Chem. Mater. 14(11), 4662-4668 (2002)

23. H. Zhang, H.Y. Xiao, Z. Chen, F.G. Liu, F.Y. Huo, S.H. Bo, L. Qiu, Z. Zhen, Improved electro-optical property by introducing stronger acceptor to thermal stable chromophores using modified julolidine as donor. Dyes Pigments 167, 245 -245 54 (2019)

24. M. Ashraf, A. Teshome, A.J. Kay, G.J. Gainsford, M.D.H. Bhuiyan, I. Asselberghs, K. Clays, NLO chromophores containing dihydrobenzothiazolylidene and dihydroquinolinylidene donors with an azo linker: Synthesis and optical properties. Dyes Pigments 98(1), 82-92 (2013)

25. M.J. Cho, J.Y. Kim, J.H. Kim, S.H. Lee, L.R. Dalton, D.H. Choi, Heterocyclic nonlinear optical chromophores composed of phenothiazine or carbazole donor and 2-cyanomethylene-3-cyano-4,5,5trimethyl-2,5-dihydrofuran acceptor. Bull. Korean Chem. Soc. 26(1), 77-84 (2005)

26. S.H. Kim, S.Y. Lee, S.Y. Gwon, Y.A. Son, J.S. Bae, D-r-A solvatochromic charge transfer dyes containing a 2-cyanomethylene-3-cyano-4,5,5-trimethyl-2,5-dihydrofuran acceptor. Dyes Pigm. 84(2), 169-175 (2010)

27. M. He, T.M. Leslie, J.A. Sinicropi, Alpha-Hydroxy ketone precursors leading to a novel class of electrooptic acceptors. Chem. Mater. 14(5), 2393-2400 (2002)

28. M.L. Zhang, H.J. Xu, C.C. Peng, H.Y. Huang, S.H. Bo, J.L. Liu, X.H. Liu, Z. Zhen, L. Qiu, Novel NLOphores containing dihexyl amino benzo[b]thiophene exhibiting good transparency and enhanced electro-optical activity dagger. RSC Advances 4(31), 15870-15876 (2014)

29. Y.P. Zhang, C.S. Liang, S.M. Jiang, A solvatochromic cyanostilbene derivative as an intensity and wavelength-based fluorescent sensor for water in organic solvents. New J Chem 41(16), 8644-8649 (2017)

30. S.S. Bag, S. Ghorai, S. Jana, C. Mukherjee, Solvatochromic fluorescent cyanophenoxazine: design, synthesis, photophysical properties and fluorescence light-up sensing of ct-DNA. RSC Advances 3(16), 5374-5377 (2013)

31. A. Kowalska-Baron, R. Zurawinski, B. Lukasik, A. Chworos, S. Wysocki, Solvent effects on the photophysical properties of distyrylnaphthalene-based conjugated oligoelectrolytes. J Lumin 192, 359-370 (2017) 
32. M. Di Donato, E. Ragnoni, A. Lapini, P. Foggi, R.G. Hiller, R. Righini, Femtosecond transient infrared and stimulated Raman spectroscopy shed light on the relaxation mechanisms of photo-excited peridinin. Journal of chemical physics 142(21), 212409 (2015)

33. V. Yurii, K. Wolfgang, A.Z. Klaas. Photophysics of 4-dimethylamino-4'-cyanostilbene and 4-azetidinyl4'-cyanostilbene. Time-resolved fluorescence and trans-cis photoisomerization. Chemical Physics 1996;211(1-3): $441-53$

34. A.K. Tawfik, From chromic switchable hydrazones to smart materials. Mater. Chem. Phys. 254, $123456(2020)$

\section{Figures}
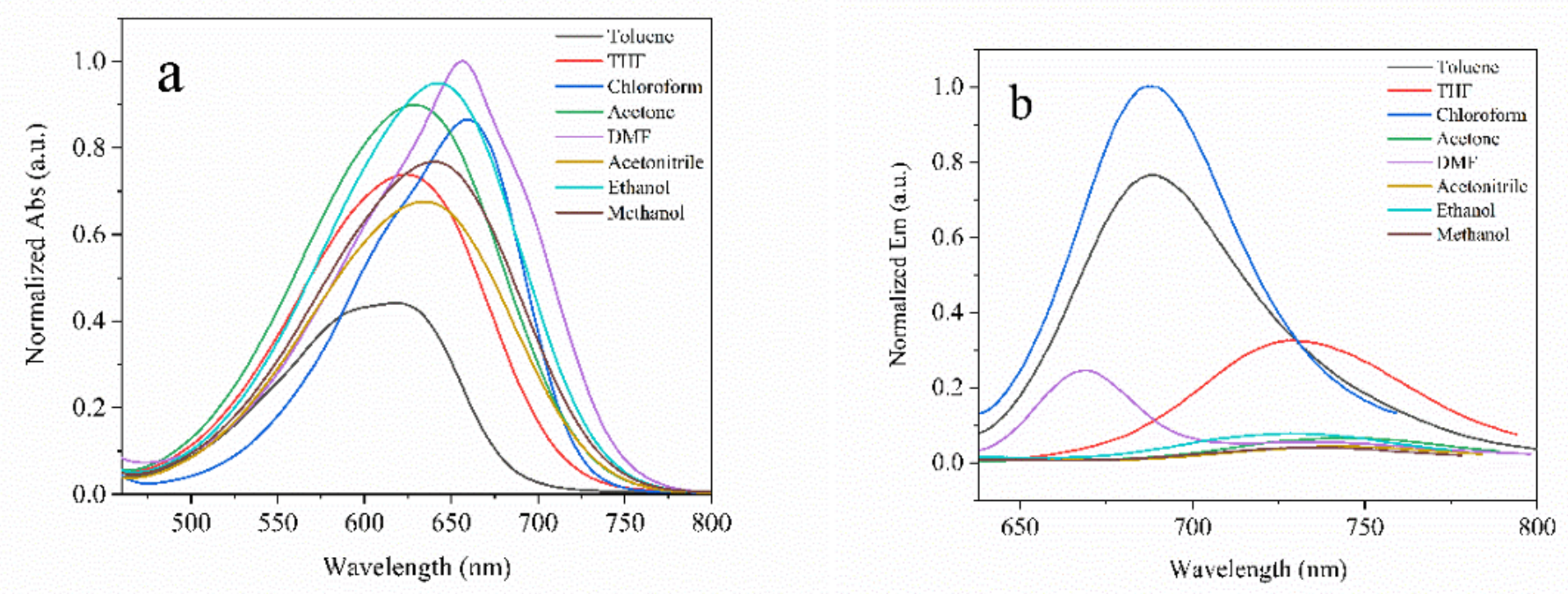

\section{Figure 1}

Absorption spectra (a) and fluorescence emission spectra (b) of dye molecules (1×10-4 mol/L) in eight solvents with different polarities 

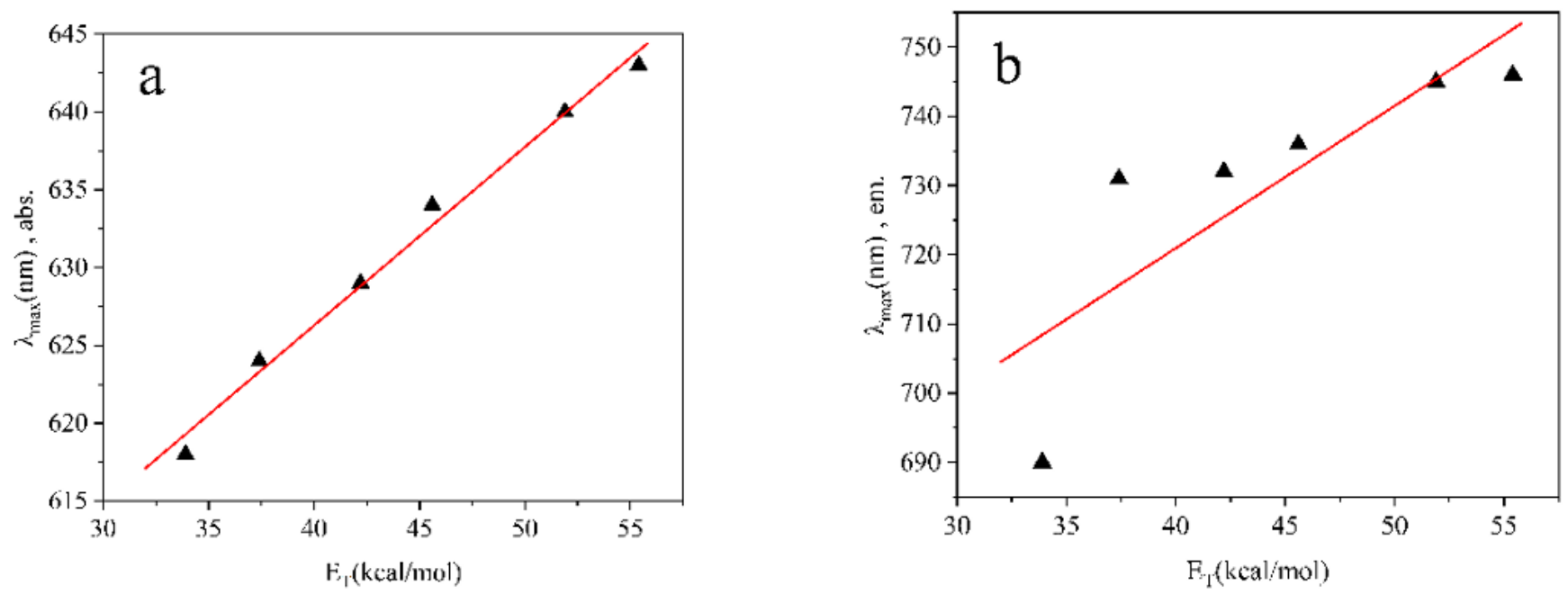

\section{Figure 2}

Plot of absorption (a) and emission(b) peaks with solvent polarity parameter ET (except chloroform and DMF)

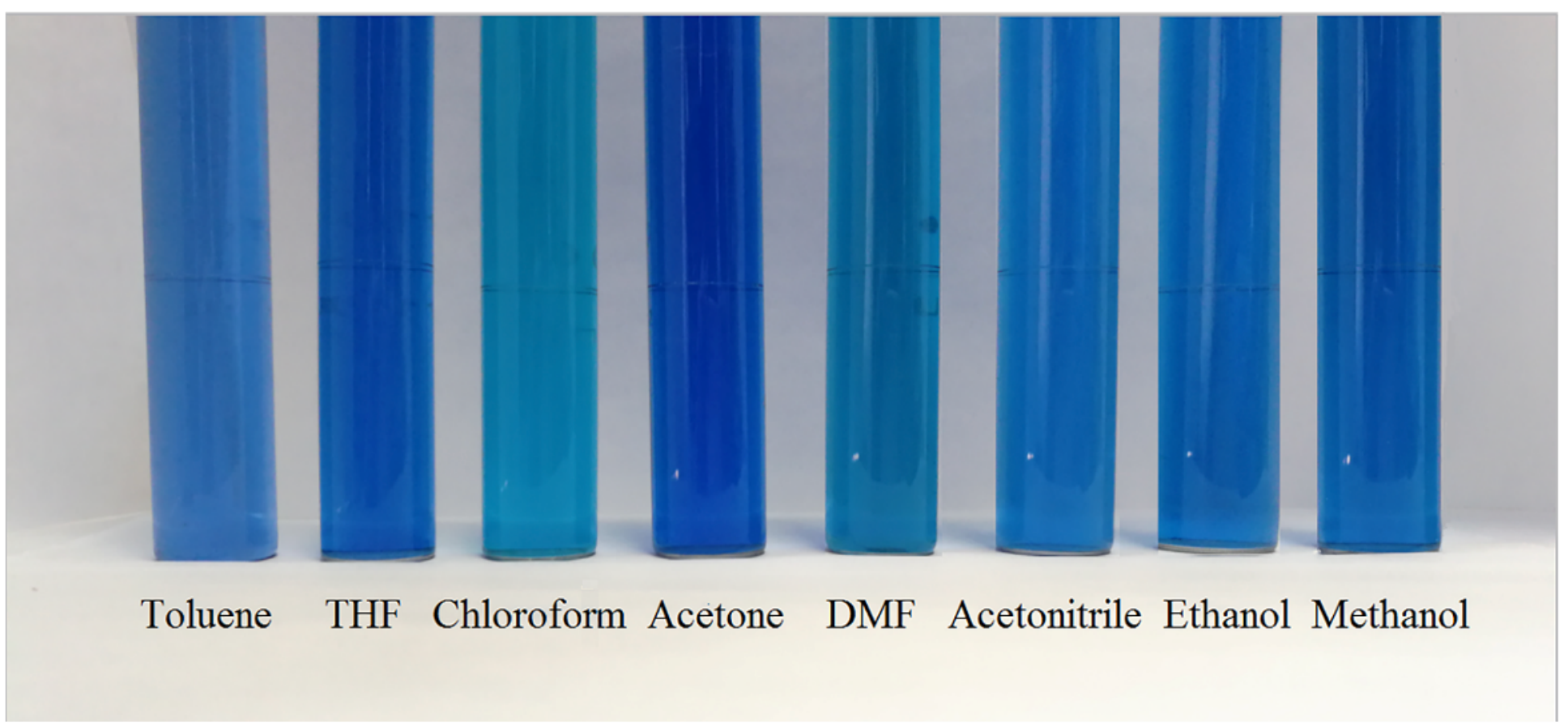

\section{Figure 3}

The photographs of dye A in several solvents 

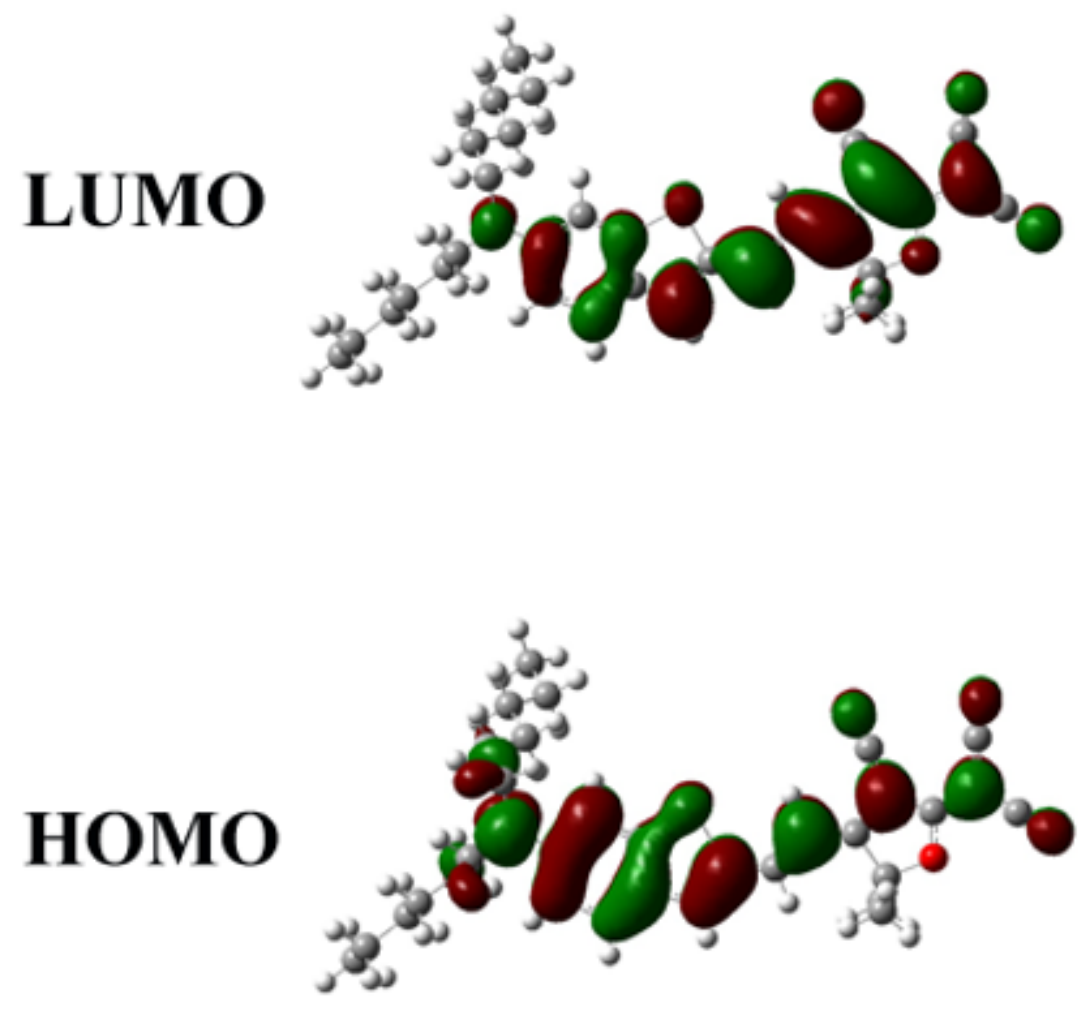

A

Figure 4

Electron distribution of the HOMO and LUMO energy levels of the dye A 


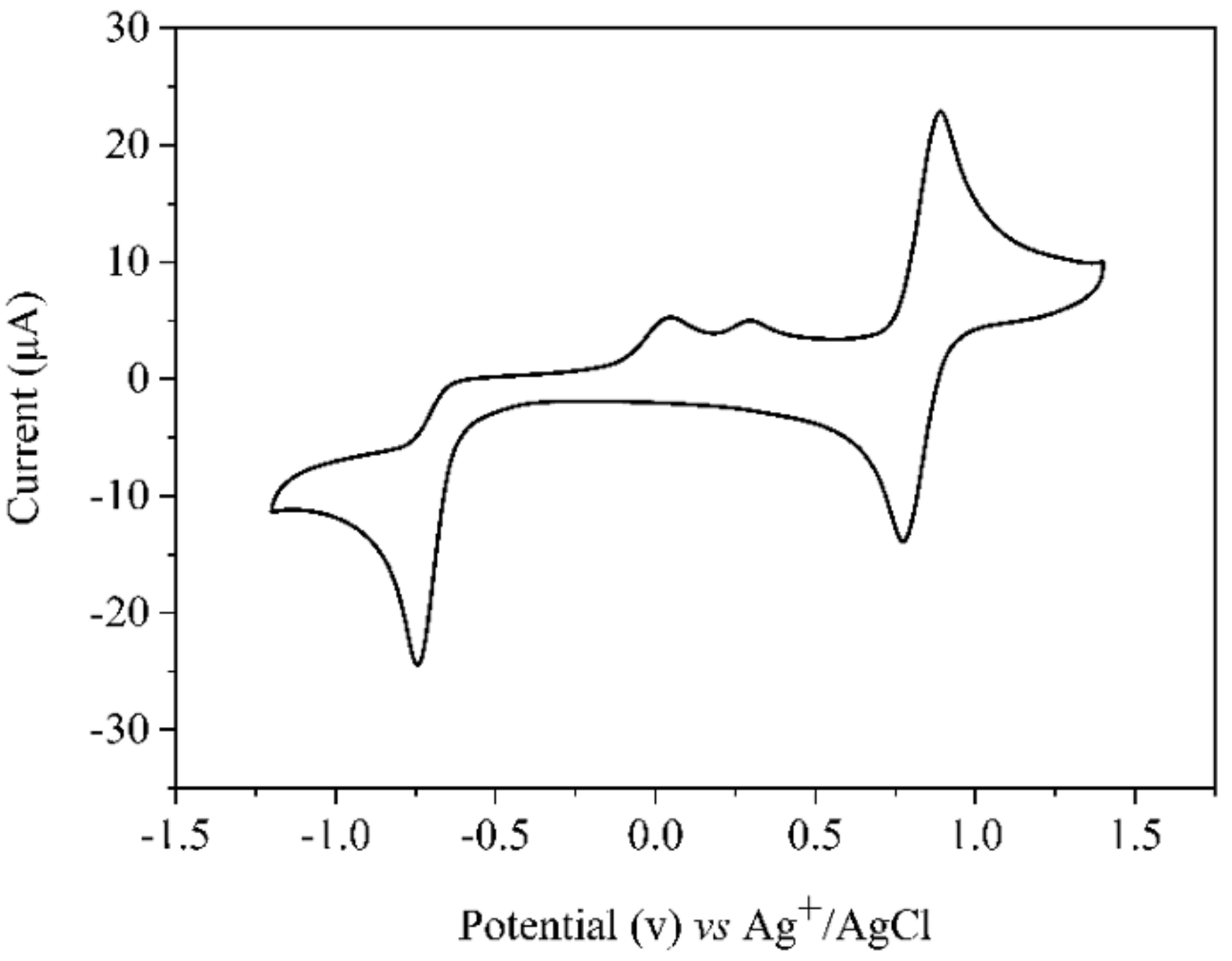

Figure 5

Cyclic voltammograms of the dye (ferrocene internal reference E1/2= $+0.43 \mathrm{~V}$ ) 

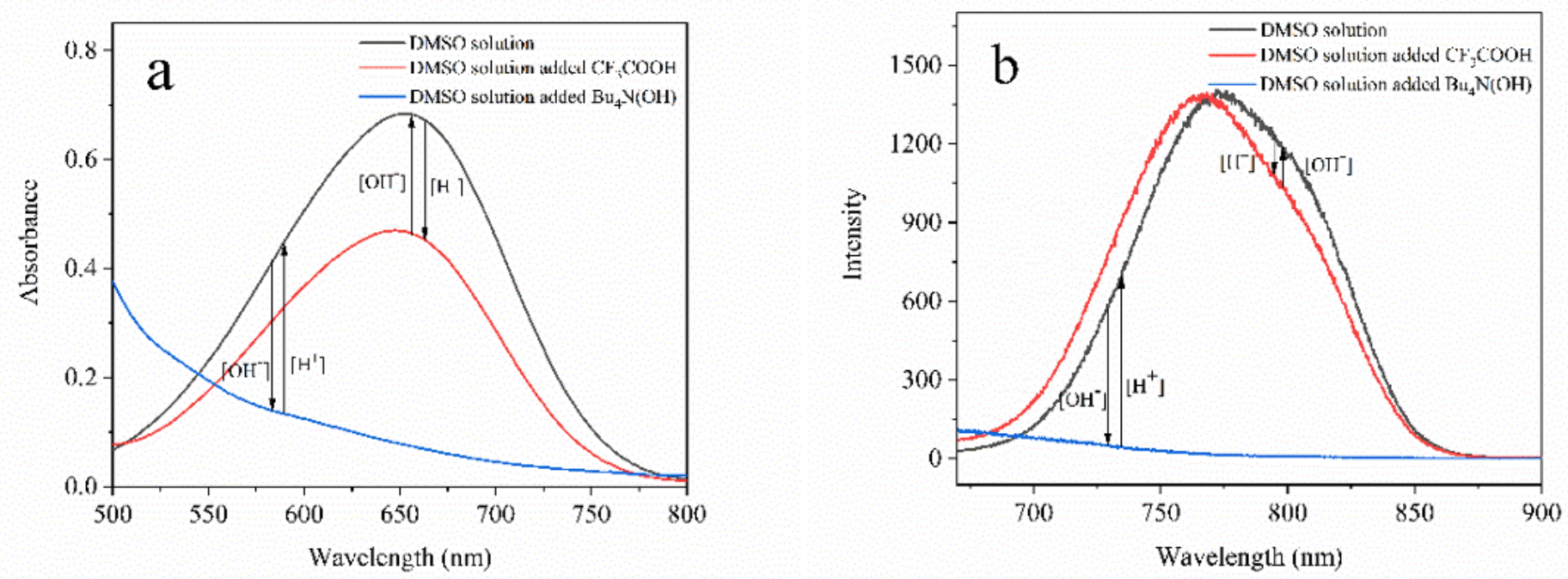

Figure 6

UV-Vis absorption (a) and fluorescence (b) changes of the dye in an acid/base DMSO solution
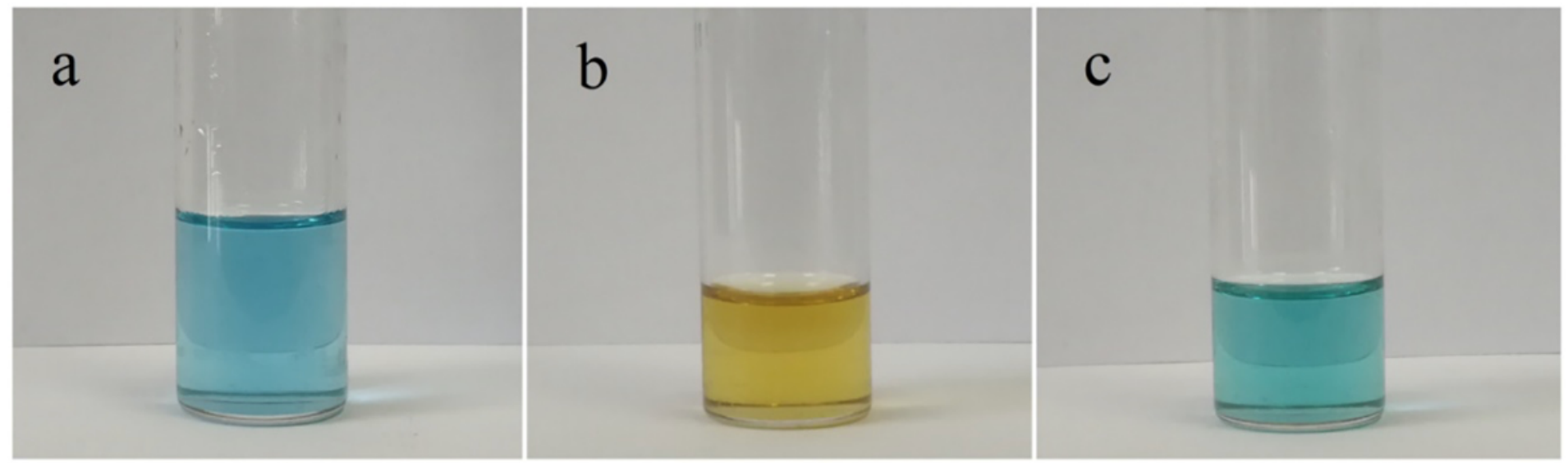

\section{Figure 7}

The Color of original DMSO solution (a), and the color of solution after adding base (b) or acid (c) (Divide the original DMSO solution (a) into two parts, and then add base and acid respectively to obtain (b) and (c)) 
a

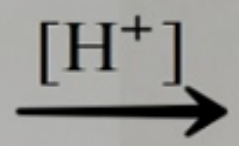

b

\section{Figure 8}

The color change when adding acid to the base-added solution (a), and adding base to the acid-added solution (b)<smiles>CCCCCCN(CC)c1ccc2cc(/C=C/C3=C(C#N)C(=C(C#N)C#N)OC3(C)C)sc2c1</smiles><smiles>CC(O)O</smiles>

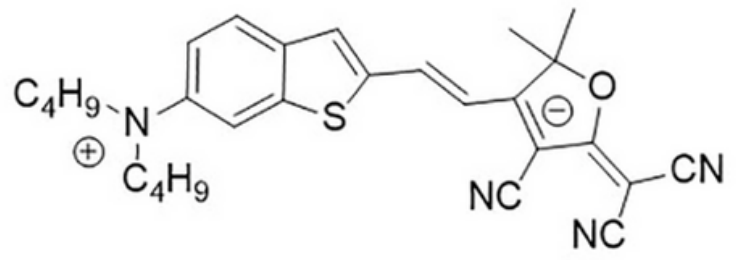

Figure 9 
The neutral and zwitterionic structures of dipolar polyene dye A with benzo[b]thiophene as donor

\section{Supplementary Files}

This is a list of supplementary files associated with this preprint. Click to download.

- Scheme1.tif 